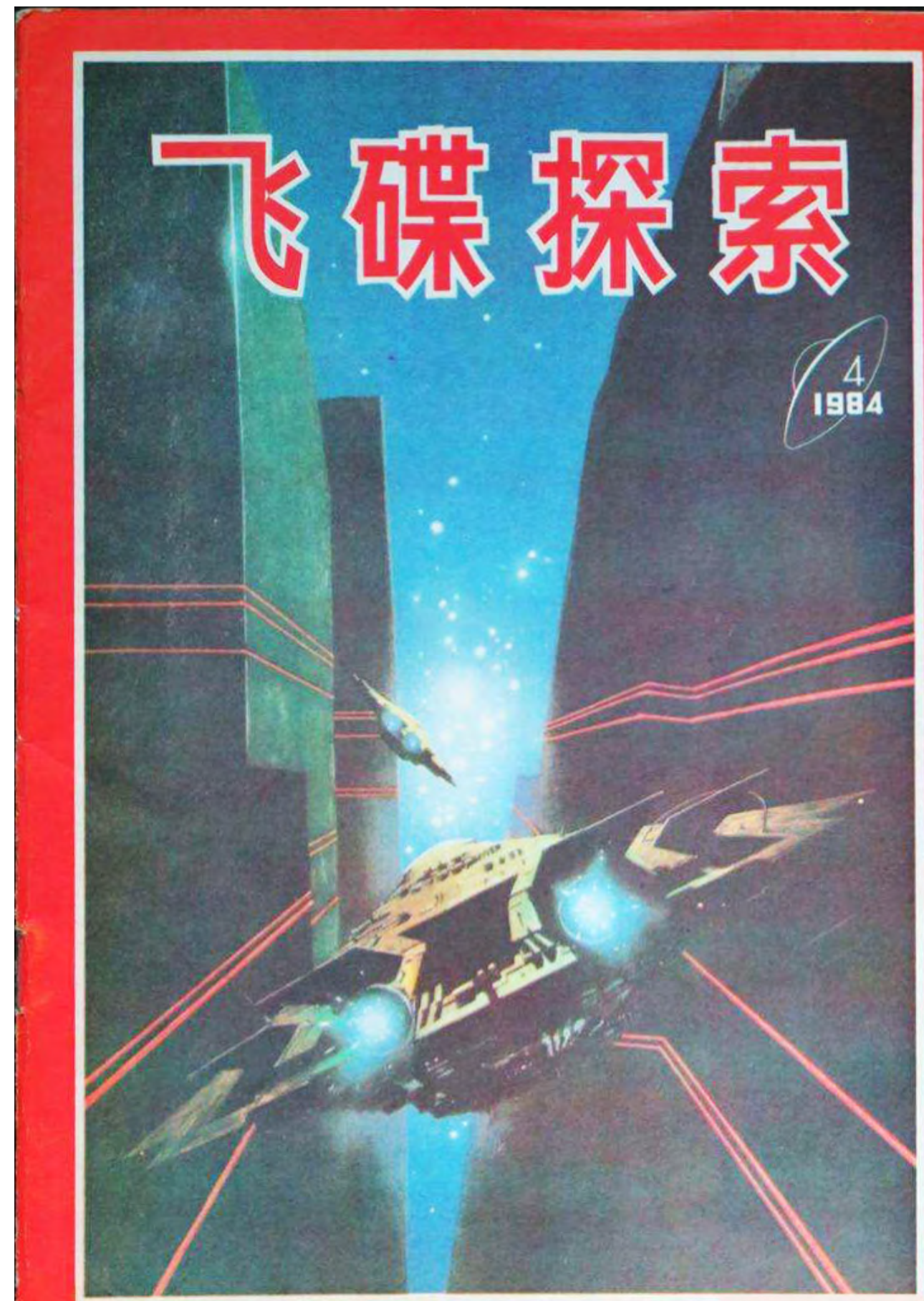

Journal of UFO Research (飞碟探索), ISSUE 4, 1984. PC: kongfz.com. 


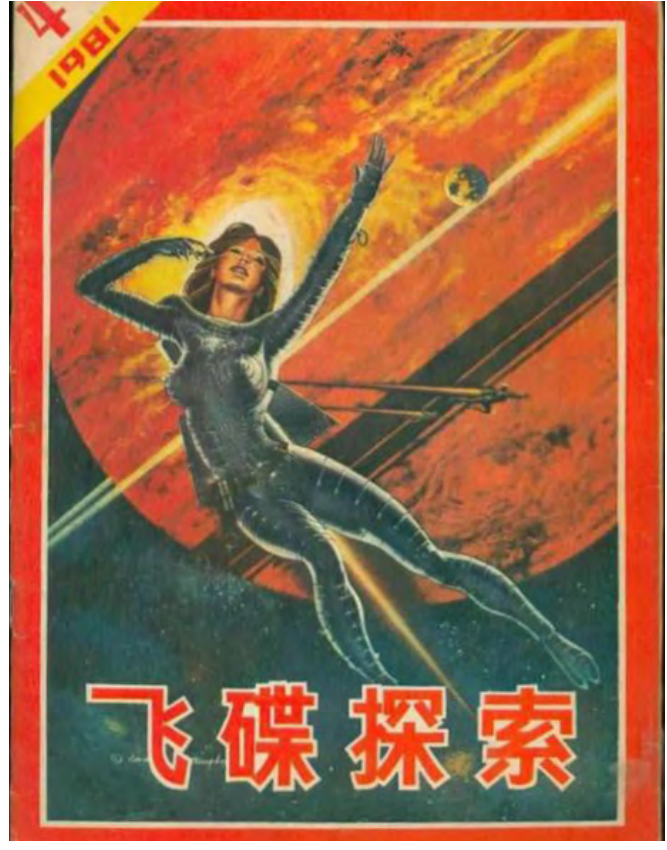

Journal of UFO Research (飞碟探索), ISSUE 4, 1981 PC: kongfz.com.

\section{On UFOlogy with Chinese Characteristics and the Fate of Chinese Socialism}

\section{Malcolm THOMPSON}

From its birth in the late 1970s, Chinese UFOlogy has passed through a series of transformations that are illuminating with respect to certain key interpretive problems around the nature and trajectories of Chinese socialism, the question of tradition and 'Chinese characteristics', and the role of science in China's modernisation. In analysing this history, this essay asks: what is the relationship between UFOlogy and socialism?
'UFO research must have Chinese

characteristics.

Liu Dongjun, 1999

"The navigation system of flying saucers is the Taiji compass.' Jiang Yongqiang, 1995

'UFOs to the people!' Ufologia radicale, 1998

W hat happened to Chinese socialism? This question was most recently asked in connection with this journal in the volume Afterlives of Chinese Communism (2019), along with a series of related questions: What legacies of the socialist tradition in China starting in the $1920 \mathrm{~s}$ still survive into the present? How have various elements of the socialist developmentalist period (1955-c. 1980) continued to shape the dynamics, trajectories, and experiences of the reform period? Where do they do this, and in what senses? How do the temporalities of the economic, political, and cultural domains interact? What do 'continuity' and 'discontinuity' mean in a historical field such as this one? Let us attempt to investigate these questions with reference to Chinese UFOlogy.

\section{The Birth of Chinese UFOlogy}

I will begin by noting a specific discontinuity whose reality is absolutely indisputable: there was no public UFOlogy in China before the reform period, and Chinese UFOlogy and the reform period began at almost exactly the same time. During the first wave of major reforms and the deepening distribution of the problems associated with the Four Modernisationsindustry, agriculture, the military, and science and technology—into the grain of everyday life, 
the China UFO Enthusiasts' Liaison Office (中国 UFO爱好者联络处) was established at Wuhan University on 20 September 1979. By May 1980, it had grown considerably and became the China UFO Research Association (中国UFO 研究会, CURA) with branch organisations in several major cities. The following February, it began publishing the Journal of UFO Research (飞碟探索), and by the mid-1980s had more than 40 branch organisations around the country and thousands of members.

In an at-this-point-unrelated development, in 1981 the All-China Qigong Science Research Association (中华气功科学研究会, QSRA) was established under the All-China Association of Chinese Medicine (中华全国中医学会). The scope and breadth of interest in this topic grew steadily in the following years until in 1986, with the blessing of national leaders like Qian Xuesen, QSRA was established as a nationallevel umbrella organisation for research and qigong practice with hundreds of member organisations. Qian was a key figure in the development of the atomic bomb in China from the mid-1950s, and the 'father' of the Chinese space programme. He was also known as 'the Tsiolkovsky of China', after the Russian rocket scientist whose work inspired not only the Soviet space programme but also numerous Soviet cultural and scientific experiments around spaceflight, biocosmism, and the imagination of a future life in space.

The QSRA immediately became the central institutional locus for paranormal research in China: extrasensory perception, telekinesis, ghosts, and so on. Certainly, as David Palmer notes in Qigong Fever (2007, 107), the 'extraordinary powers' (特异功能) that qigong practice was supposed to engender according to the QSRA were not exactly coextensive with the domain of 'the paranormal', but in seeking to develop and theorise these powers, continuous reference was made to these fields of study, and especially to scientific experiments in these areas in Western countries. Between 1986 and the early 1990s, the organisation changed its name in minor ways and fell from time to time under the supervision of different ministries.
By 1993, it operated as a 'state-level social organisation' (国家一级社团组织) under the Ministries of Health and Civil Affairs.

All of this occurred in exactly the period when the previously uncommon phrase 'with Chinese characteristics' (具有中国特色) was being driven into public discourse, after Deng Xiaoping had used the phrase 'socialism with Chinese characteristics' in his opening speech at the Twelfth National Congress of the Chinese Communist Party on 1 September 1982. It quickly became a central element in the discursive rearrangements that occurred through the 1980s around the problems associated with dismantling many of the social and economic modes of organisation that had characterised the socialist developmentalist period, opening social life to new forms of knowledge and culture from the 'advanced' capitalist countries, developing an 'advanced' culture and economy, and so on. There is little doubt that this had a great deal to do with the end of official Chinese socialist internationalism and the redirecting of attention and desire toward the capitalist world, but the problem of 'Chinese characteristics' also became an important site in which struggles over the legacy and worth of Chinese socialism could take place. The fact that the content of this term often seems unclear was not a function of any deliberate murkiness or basic obscurity, but rather of the fact that it quickly became a central stake in entirely specific and practical struggles. As we will see, this is true in Chinese UFOlogy as well.

\section{Qigong UFOlogy}

By the early 1990s, then-the period immediately following the crushing of the 1989 social movement and the subsequent dismantling of the institutional and discursive resources that pertained to certain forms of protest against the process of reformthe broad project of combining Chinese traditions like qigong with 'high-level science 
and technology' (高阶科技) in the interest of economic development was well-established. It intersected with, and developed alongside, the popular mass movement known at the time as 'Qigong Fever' (气功热), in which, among other things, charismatic Daoist masters would distribute their healing $q i$ to their followers via electronically mediated speech at rallies of thousands or even tens of thousands of people, many of whom fell into collective trances or were healed of injuries or ailments. Traditional Chinese medicine (acupuncture, moxibustion, etc.) had occupied a fairly stable and prestigious place in the apparatus of socialist public health since the 1950 s, but recuperating the religious discourse it had developed with historically, and bringing it into relation with the fourth modernisation, as the QSRA did, created all kinds of new possibilities under the general problem of 'the organic combination of Eastern qigong culture with Western modern science' (东方气功文化与西方现代科学的有机 结合) (Jiang 1995b, 31).

Take, for instance, the book A Summoning to the Idea of the Source of Life (生命源头 的意念呼唤), commonly known as Eastern UFOlogy (东方飞碟学), published by the director of the Guangdong School of Flying Saucer Technology (广东飞碟技术学校) Lin Qingquan in 1993 and favourably reviewed in the magazine China Qigong (中国气功) in 1995. Here, the fundamental principle (基础理论) of Eastern UFOlogy is, precisely, the combination of 'Eastern Yijing principles' (东方易理) with 'Western mathematical formalisation' (西方数 理) (on the Yijing, see also Matthews's essay in the present issue). With the theoretical application (理论应用) of these to the problem of flying saucers and aliens, Lin attains the following:

1. The principle of flight of flying saucers is yin (隐, 'secret', 'hidden') flight. This is similar to the connotation of people with extraordinary powers (特异功能, again). The particular characteristic of yin flight is that the speed of light is controlled by thought, causing the moving body to alternate between empty (虚) and full (实) forms, between the manifest (显) and the hidden (隐).

2. The power source of flying saucers is spiritual thought. Flying saucers rely on controlling the release of the power of thought to set off the internally-produced spin acceleration of their flight system, so that the negative information flow that their thought sends out fires the spin velocity of its particle device, causing it to accelerate its spinning, and in a very short time to surpass the speed of light, so that, by becoming negative, it enters the realm of four dimensional space.

3. The navigation system of flying saucers is the Taiji compass (太极罗盘). In the boundlessness of space, where is the destination? How is navigation accomplished? One must use the Taiji compass to go out to interstellar space distances and time intervals, to pass through the conversion of time and space into four-dimensional pure negativity, which is the time-tunnel between the starting point and the destination.

4. Aliens, like the qigong masters of Earth, can directly absorb the yin capacities of the universe and are thus able to avoid the necessity of eating and dressing; they can reside anywhere, refusing grains year in and year out to attain immortality, without suffering from freezing or being susceptible to cold diseases. The aliens live in all sorts of simple saucer-shaped flying machines, roaming about freely, floating endlessly in time and space. (Jiang 1995b, 31)

Setting the particular content aside for the moment, the condensation of previously-and perhaps 'properly'-separate vocabularies and concepts into a single text that we find here would not, in and of itself, have seemed very 
strange within the terms of qigong discourse in the 1990s. But that is not to say that it was satisfactory to everybody.

The China UFO Research Association had been affiliated with the QSRA since January 1988 as a 'second-level study society' (二级 学会), and by this route had acquired legal standing as an organisation. But this led to all kinds of 'internal contradictions' (内部矛 盾) between the 'materialist' UFOlogists and the qigong tendency (Jiang 1995a, 213-215). This came to a head at CURA's fourth national congress in Beijing in May 1992, at which many members became frustrated by the infiltration of 'pseudoscience' (伪科学), leading the organisation to reiterate its commitment to 'the dialectical-materialist guiding principle' (辩证唯物主义指导原则) (Xinhua 1992).

\section{Dispersal and Reconstitution}

The most famous element of the popular qigong-UFOlogy matrix described here is, of course, the Falun Gong, which entered the QSRA with its leader Li Hongzhi in July 1993. It is unclear what role this event had in further dividing UFOlogy into what can only be described as a two-line struggle, but it would certainly lead to major problems for the movement. Li's own beliefs about aliens and UFOs are relatively well-known, but the question here is how the Falun Gong's involvement in the broader qigong movement affected the UFOlogists.

In the post-1989 context, close watch was kept on developments within the organisations that broadly constituted 'civil society' in China, with Party members often joining groups or creating Party branches within them. Being thus regularly apprised of what they considered the increasingly strange developments within the qigong movement-and particularly in the Falun Gong-and as Qian Xuesen's political influence over science in China began to wane, sections of the Party began a media campaign against pseudoscience in 1995, which continued and intensified over the following years. The Falun Gong withdrew from-or was thrown out of, accounts differ-the QSRA in March 1996, but this in no way saved the latter and the broader movement from continuing to experience internal struggles and problems with the state.

In September 1997, as a result of what contemporary UFOlogists call its 'implication in extraordinary political events in China', CURA lost its status as a second-level study society under the QSRA and was 'compelled to disband', after which branch organisations survived independently and more or less underground, 'wandering about like lost children with no home, totally unsure of what to do' (ICUA 2019). The Dalian branch took the initiative in reconstituting an umbrella organisation, and in September 1998 a conference was held there with delegates from all over the country. Out of the discussions that took place there emerged plans for a new organisation, which was established in April 1999 as the International Chinese UFO Association (世界华人UFO联合 会, ICUA), registered in Hong Kong. This is the largest organisation of Chinese UFOlogy today, though it is certainly not the only one.

\section{Maoist UFOlogy?}

This is the situation in which we discover a very different kind of recuperation of Chinese traditions for the accomplishment of national goals, for instance in the article 'UFO Research Must Have Chinese Characteristics' (UFO 研 究必须具有中国特色) by Liu Dongjun, which appeared in the October 1999 issue of the popular science monthly Scientific Chinese (科学中国人). The principles of UFO research here have nothing whatsoever to do with qigong modes of explanation, and its methods resemble nothing so much as a socialist developmentalist-era mass campaign: 
1. We must adhere to the materialist point of view, use the scientific method and strategy of seeking truth from facts, discard the false and retain the true, and seriously explore causes and laws of transformation. In the boundless universe, nothing is so bizarre that it cannot exist. But no matter how magical it is, as long as it is an objectively existing substance, there will necessarily be laws of transformation for its emergence, development, and decline. Only by using the materialist standpoint and method can we reach conclusions that accord with objective reality and the nature of science. We must put an end to the idealist conception of history, and refrain from unrealistic fantasies or deliberate mystification.

2. We must achieve the unity of experts and the masses, set up observation points widely, establish an observational and information network, and lay out a tight nationwide network concentrated on observation and capture. Whether a UFO phenomenon is an atmospheric or photoelectric phenomenon or an emissary from the stars or anything else, if we wish to reveal its true face, we must adopt the method of the unity of experts and the masses. Every province, every city, every region, even every county, and especially remote and fortification areas-all of these require the setting up of observation points and the presence of observation personnel.

3. We must have the spirit of perseverance, devotion, and life-long struggle. Tackling key problems for science and being devoted to humanity-this is the spirit of the age, the sacred duty of the descendants of Yan and Huang, a lofty and glorious enterprise. Every comrade who is earnest about UFO exploration and research should possess this spirit of tenacious struggle and dedication. This way, we will walk at the forefront of the world's nations in UFO exploration and research and achieve amazing results that will attract the attention of the world. (Liu 1999, 78)

In this obviously aspirational text-it would be inane to point to this aspect of it as a shortcoming-the legacies of Chinese socialism have a great deal to offer not only to UFOlogy but also to science as a global enterprise and, further, to the preparation of the ground for imagining a future in which the coordinates of human endeavour are cosmic rather than merely terrestrial. Here, the elements of 'Maoist' forms of epistemology, practice, and personal commitment are conjoined to a form of science that is, at least in principle, open to any possible future.

\section{The End}

Unfortunately, perhaps, this document carries no sign of having been at all influential. The form of UFOlogical discourse that has been dominant in China since the formation of the ICUA-which one can follow in the pages of The Journal of UFO Research or in the conference reports that appear on the association's website, or in its newsletter, UFOlogy (飞碟报)一is exclusively concerned with cataloguing encounters, breathlessly excavating possible references to UFOs and aliens in 'ancient times' in China and elsewhere, compiling reports from global UFOlogy, and ruminating harmlessly on the possible nature of an 'interstellar civilisation' (星际文 明). A bleak seriality of endless, untheorised repetition, as the Italian collective Men in Red put it in its magazine Ufologia radicale in 1998 (7-8), devoted to no programme beyond establishing the reality of the phenomenon, and no longer really committed to even that beyond the community of people who already accept it. Chinese UFOlogists in the 1990s, like many other fields of social activity, attempted to establish a UFOlogy with Chinese 


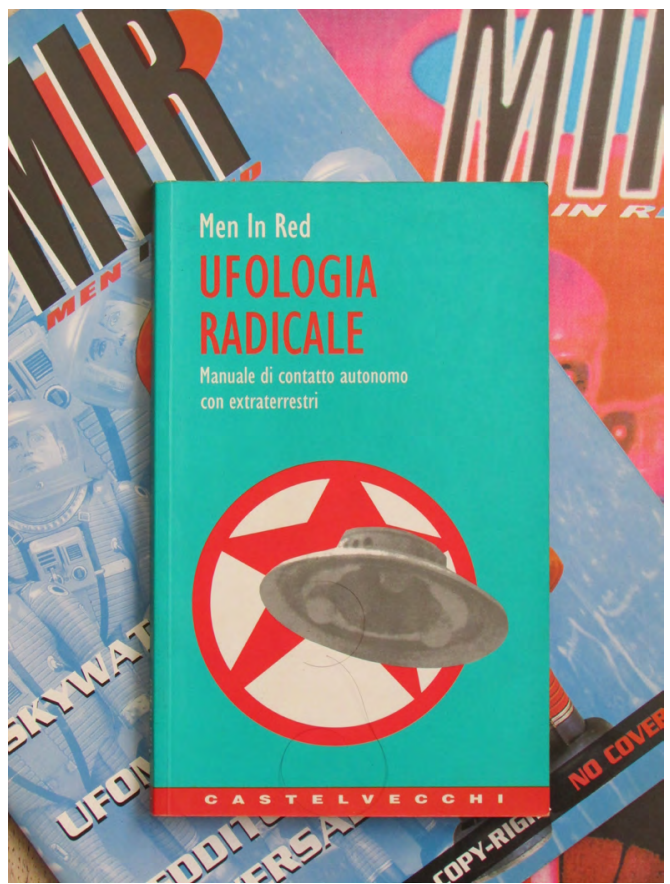

Ufologia Radicale, by the Italian Collective Men in Red.

characteristics in very different ways. But with the stamping out of radical qigong thought and the disappearance of mass mobilisation in the field of science, Chinese UFOlogy, insofar as it officially exists, ceased to differ from the UFOlogy of the History Channel or the glossy UFO magazines in any discernible way. But another UFOlogy was possible.

Where manifestations of alien contact do appear that may involve something more than this, the agents (official and unofficial) of the China Anti-cult Association (中国反邪 教协会), created in October 1999 precisely in the suppression of the Falun Gong, are ever vigilant and waiting to expose them. This happened, for instance, last year when Liu Boyang, a PhD student in astrophysics at the National Astronomical Observatory under the Chinese Academy of Sciences, launched a public campaign to denounce online cult tendencies around aliens (Chen 2019a), which prompted Chen Xingqiao of the China Buddhist Association to write the lengthy 'Study of the Cult Teachings of “Alien Systems”' (“外星”系邪 说研究) on behalf of the Anti-cult Association, currently posted on the website of the People's Government of Jinghe county, Xinjiang (Chen $2019 b$ ). With so much of the state apparatus today committed to policing and preventing the emergence of new things and actually existing UFOlogy in China in such a moribund condition, we are far away now from the possibilities that existed in the 1990s for either a Chinese UFOlogy or a socialist UFOlogy. 
This text is taken from Made in China Journal: Volume 5, Issue 2, 2020 , edited by Ivan Franceschini and Nicholas Loubere, published 2020 by ANU Press, The Australian National University, Canberra, Australia.

doi.org/10.22459/MIC.05.02.2020.13 